\title{
Hermenêutica Feminista da Suspeita como possibilidade de superação de epistemologias teológicas excludentes
}

Feminist hermeneutics of suspicion as a way of overcoming excluding theological epistemologies

JACI DE FÁtIMA SOUZA CANDIOTTO ${ }^{a}$

\section{Resumo}

O artigo desenvolve uma das dimensões da hermenêutica teológica, que pode ser denominada de hermenêutica feminista da suspeita. Ela objetiva confrontar os textos canônicos reconhecidos como patriarcais e distinguir entre sua roupagem cultural e a mensagem a ser transmitida. A suspeita reside nessa roupagem, que normalmente associa a mensagem divina a uma linguagem e significação masculinas, a partir quais as mulheres parecem estar ausentes ou inativas. A hermenêutica feminista da suspeita objetiva reposicionar as mulheres e realçar suas ações no seio dos textos sagrados e eclesiais, de maneira que deixem de ser desqualificadas como meras coadjuvantes e auxiliares. Em um primeiro momento, estuda-se a relação entre hermenêutica teológica e hermenêutica teológica feminista; em seguida, o artigo especifica a hermenêutica da suspeita, especialmente como ela é praticada pela teóloga Elsa Tamez.

Palavras-chave: Hermenêutica. Suspeita. Mulheres. Bíblia. Teologia.

\section{Abstract}

The article develops one of the dimensions of theological hermeneutics, the so-called feminist hermeneutics of suspicion. It faces canonical patriarchal texts distinguishing

\footnotetext{
a Pontifícia Universidade Católica do Paraná (PUCPR), Curitiba, PR, Brasil. Doutora em Teologia, e-mail: j.candiotto@pucpr.br
} 
their cultural layers from the message they carry. The suspicion is regarding this covering that connects divine message to masculine language and signification in which women appear to be absent or inactive. A feminist hermeneutics of suspicion aims at repositioning women and highlighting their actions within sacred and ecclesial texts in a way that they are not disqualified as mere supporting characters anymore. At first, the relationship between theological hermeneutics and feminist theological hermeneutics is studied; then, the article specifies the hermeneutics of suspicion, especially as it is practiced by the theologian Elsa Tamez.

Keywords: Hermeneutics. Suspicion. Women. Bible. Theology.

\section{Introdução}

A hermenêutica teológica feminista é orientada principalmente à interpretação da Bíblia. Ela é composta de diversos movimentos que transbordam a hermenêutica teológica tradicional. Estes movimentos apresentam novas perspectivas de interpretação dos textos escritos, sem a pretensão de se constituírem em novo método teológico.

A teologia feminista adota, em certo aspecto, métodos já consolidados, tal como o histórico-crítico ${ }^{1}$, pelo qual o texto sagrado é compreendido pelo contexto em que foi escrito". Trata-se de propor "uma interpretação daquilo que está presente na estrutura da significação do texto, mas que não pertence necessariamente à intenção da obra" (TEPEDINO, 1990, p. 18). Esta estrutura da significação é estudada, pois, pelo contexto em que os textos foram escritos e, principalmente, a época em que eles são lidos e interpretados.

O horizonte desta leitura e interpretação é, ao mesmo tempo, crítico e transformador, conforme estratégia inaugurada pela teologia da libertação. A partir dela, considera-se que a Bíblia pode ser usada como mecanismo de opressão, como também veículo de libertação. Até neste ponto, a

\footnotetext{
${ }^{1}$ Não discutiremos nesse trabalho a pertinência do método histórico-crítico. Remetemos, entretanto, aos primeiros biblistas que desenvolveram este método: BULTMANN, 2000; CULLMAN, 2001; BORNKAMM, 2003. Para os limites do método histórico-crítico na exegese atual, ver: NOGUEIRA, 2019, p. 296-310.

2 Muitos dos elementos da abordagem contextual são derivados dos Círculos Bíblicos e da Pastoral Bíblica, explicitados principalmente pelo biblista Carlos Mesters. Ela também é contemplada no documento eclesial: PONTIFÍCIA COMISSÃO BÍBLICA, 2004.
} 
hermenêutica teológica feminista absorve elementos de outras maneiras de se fazer teologia.

Todavia, a hermenêutica teológica feminista transborda essas leituras porque ela interpreta a Bíblia não somente em sua dimensão religiosa, mas também em sua "dimensão cultural, social e política, pois é uma matriz formadora da sociedade ocidental e cristã" (TEPEDINO, 1990, p. 15). Esta leitura jamais se limita a uma interpretação unilateral, envolvendo a tomada de posição que se opõe a qualquer interpretação neutral e objetivista do texto sagrado.

No primeiro momento deste artigo apresentamos as principais intersecções entre a hermenêutica teológica tradicional e a hermenêutica teológica feminista, ao modo de breve contextualização da própria hermenêutica teológica. No segundo momento, faremos uma análise mais específica da hermenêutica da suspeita.

\section{Hermenêutica teológica e hermenêutica teológica feminista}

A Hermenêutica é conhecida como a ciência da interpretação. A etimologia da palavra vem do verbo grego, hermemeuein, que significa interpretar ${ }^{3}$. Fundamentalmente, trata-se da ação interpretativa sobre textos escritos. Fazer a hermenêutica de um texto envolve admitir sempre um excesso de significado sobre seu significante, um resto não necessariamente formulado do pensamento que a linguagem, intencionalmente ou não, deixou na sombra.

\footnotetext{
3 Por sua vez, hermeneuein, que tem como raiz herme, foi atribuída ao mitólogo Hermes, tido como o mensageiro dos deuses. Ele foi considerado o inventor dos meios elementares de comunicação, particularmente a linguagem e a escritura. Sinteticamente, Hermes é o mensageiro entre os deuses e os homens, interpretando aos últimos a mensagem dos primeiros (Cf. MARTÍNEZ, 1984, p. 16). Entretanto, no entender de Ferraris, "o sentido originário da palavra, hermenéia, é a eficácia da expressão linguística, que hoje se considera, e com razão, como o alfa e o ômega da hermenêutica. Por isso, Heidegger e Gadamer, no rastro da ideia de própria língua nas tradições do humanismo e do romantismo, conectam a experiência hermenêutica ao universo da linguagem e do logos (no caso aqui, discurso) como verbum (palavra) e como sermo (falar com, discursar,...)." (FERRARIS, 2000, p. 9).
} 
Resulta que nenhuma interpretação é absoluta, posto que jamais um significado exaure seu significante originário. No caso da hermenêutica teológica, a interpretação incide especialmente sobre as Escrituras cristãs.

Clodovis Boff identifica três acepções distintas e em escala crescente da noção de Hermenêutica, no campo teológico:

1. A de uma canônica da interpretação exegética. Aqui nos deparamos com o sentido etimológico do termo hermêneutikê technê; 2) A acepção de interpretação como tal, isto é, de exegese como operação de decifração, incluindo seu resultado. Poder-se-ia então falar aqui de uma hermêneia, em oposição à noção anterior - a da hermênenutikê technê; 3. Enfim, a Hermenêutica pode ser simplesmente considerada como sinônimo de Teologia, enquanto esta tem por tarefa a compreensão de um sentido originário hoje e para hoje. Segundo esta acepção maximizante, a Hermenêutica teológica corresponderia ao que nós chamamos 'teoria teológica'. Assim, por ex., haveria uma 'Hermenêutica dos Sinais dos Tempos', uma 'Hermenêutica da História', uma 'Hermenêutica Política', etc. (BOFF, 1978, p. 239-240).

Nessa última acepção, a hermenêutica teológica procura reposicionar o texto bíblico no seu significado originário a partir do contexto em que foi escrito (na tentativa de recuperar um sentido para aquém do texto). Em seguida, ela busca compreendê-lo pela atualização de sentido que a comunidade interpretante lhe atribui (na busca de criação de um sentido que não se limite ao próprio texto).

Em teologia, este movimento costuma ser chamado de círculo hermenêutico ${ }^{4}$, que se desdobra na relação entre Palavra de Deus e Escritura, Criação de Sentido e Acolhida de sentido, Estrutura e Sentido, Presente e Passado, Técnica e interpretação5

Em primeiro lugar, a hermenêutica teológica considera Palavra de Deus e Sagrada Escritura dois elementos relacionáveis, mas não idênticos. Há desníveis e diferenças entre eles. A Palavra de Deus somente é uma regula fidei, norma normans da Fé, em um contexto de uso ou significação. Assim, dizemos

\footnotetext{
${ }^{4}$ Expressão cunhada e generalizada por P. Ricoeur (1965) a partir do §3: Verstehen und Auslegung, de Ser e Tempo (Sein und Zeit), de Heidegger (Cf. HEIDEGGER, 2012, p. 421-434).

${ }^{5}$ Aqui acompanhamos Boff,1978, p. 243-250, mas também Croatto, 1986, p. 36-58.
} 
que a Escritura somente é norma se for lida na tradição eclesial, apreendida na relação com a Comunidade viva (sensus fidelium). Por isso mesmo a Escritura é também norma normata, já que a Tradição é meio de origem e de audição da palavra. Os textos escriturísticos foram escritos em contextos cosmológicos, culturais, literários, políticos específicos. Desse modo, ao se tomar distância tanto da identificação da Palavra de Deus com a letra da Escritura, quanto de sua equiparação à comunidade auditora ou leitora, afirma-se que ela se encontra na dinâmica da relação "nunca perfeitamente objetivável” (BOFF, 1978, p. 245) entre ambas.

Em seguida, o círculo hermenêutico pode ser situado pela articulação dialética entre acolhida de sentido e doação (criação) de sentido. Tem-se a acolhida da Palavra, a fidelidade à letra do cânon e a positividade dos acontecimentos do passado narrados pela Escritura. Contudo, o que um acontecimento significou para aqueles que o vivenciaram difere do significado que foi acrescentado durante a "distanciação" dele. Croatto chama essa leitura do acontecimento (bíblico) de "reserva-de-sentido". Com isso, aponta a um mais-de-sentido "que não era visível no momento de sua própria realização". Não se busca repetir o sentido dos fatos originais (como, por exemplo, a libertação da escravidão egípcia), ou lê-los "como se tivessem acontecido na forma em que estão contados", como quer a leitura historicista, mas explorar sua "reserva-de-sentido". "Os acontecimentos que dão origem a um povo não se esgotam em sua primeira narração, mas 'crescem' em sentido através de suas projeções na vida daquele" (CROATTO, 1986, p. 37-38). Pretende-se, pois, doar um sentido relevante para o projeto presente da comunidade, sem prejudicar a positividade do passado e a fidelidade à palavra.

Quando inexiste esta dialética, desliza-se para os extremos daquilo que Clodovis Boff chama de "biscateação hermenêutica" e "positivismo semântico" (BOFF, 1978, p. 246). "Biscateação" como uma maneira de traduzir o termo francês bricolage, utilizado por Lévi-Strauss em $O$ pensamento selvagem, no sentido de que a ciência que se ocupa deste pensamento, constrói mitos diferentes com os mesmos elementos que têm à sua disposição. De maneira análoga, a "biscateação hermenêutica" consiste na atitude que extrai da Escritura somente aquilo que é objeto do próprio interesse, sem 
contextualizá-lo em um horizonte maior. Em consequência, se a significação que serve para algo se apresenta como adequada, pode-se chegar a uma miscelânea incoerente de interpretações. Já o positivismo semântico, consiste na atitude que pretende catalogar e arquivar o texto para, em seguida, usá-lo de acordo com o capricho do momento. O perigo desta posição é congelar e enclausurar as novas possibilidades de significações. Ambas as tendências são extremistas e dogmáticas, já que não levam em conta a permanente relação entre leitor e texto, comunidade e Palavra.

Quanto ao círculo Estrutura - sentido, procura captar antes a estrutura autônoma do texto do que lhe atribuir um sentido imediatamente. A explicação seria o momento prévio na sequência da qual a compreensão é possível, sendo uma o apoio da outra ${ }^{6}$.

O círculo Presente - Passado, por sua vez, indica que a Bíblia, como qualquer outro texto escrito, retém e ao mesmo tempo libera sentido. Ela existe para poder ser lida e relida, sendo o presente histórico do leitor o critério de sentido. Se, primeiramente, objetiva-se encontrar a "Palavra sob a escritura, o Espírito sob a letra, agora, procura-se o Sentido no presente, a Palavra no tempo, o Espírito na História, mas tudo isto através do próprio sentido da Escritura" (BOFF, 1978, p. 248).

Finalmente, o círculo technê hermêneutikê — hermêneia adverte que se o sentido não pode ser fixado absolutamente, não qualquer sentido pode ser apreendido. A técnica hermenêutica traça os limites do espaço de aparição do sentido, mas a hermenêutica é incapaz, somente por seus meios técnicos, de estabelecer o sentido mais adequado. Aí é que se torna possível o momento criativo da doação de sentido, no espaço aberto e circunscrito pela técnica hermenêutica. A técnica hermenêutica identifica o convite, o apelo e a interrogação da Escritura, mas seu sentido só se completa pela e a partir da

\footnotetext{
${ }^{6} \mathrm{O}$ círculo hermenêutico tenta conciliar posturas filosoficamente conflitivas. "Enquanto toda aproximação hermenêutica de um texto pressupõe a possibilidade de descobrir o sentido originário, oculto, sob a letra, as novas teorias de leitura, particularmente a análise estrutural, não postulam nenhuma teoria de duplo sentido e se aplicam unicamente às estruturas internas do texto" (GEFFRÉ, 1989, p. 34). Quer dizer, a produção de sentido no estruturalismo é redutível à relação dos sinais entre um conjunto de significantes. Não se invoca a relação entre significante e significado, como se observa na hermenêutica.
} 
resposta do interpelado em sua vida concreta. Assim delimitada, toda interpretação é inovadora.

Após essa primeira incursão pela hermenêutica teológica, cumpre-nos identificar seus desdobramentos na hermenêutica feminista?.

Segundo a Pontifícia Comissão Bíblica (2004, p. 79), "a hermenêutica feminista não elaborou um método novo. Ela se serve dos métodos correntes em exegese, especialmente do método histórico-crítico". Ressalta ainda o documento que "deve-se distinguir várias hermenêuticas bíblicas feministas, pois as abordagens utilizadas são muito diversas" (Pontifícia Comissão Bíblica, 2004, p. 78).

Poderíamos dizer que essa teologia revisita a hermenêutica quando ela segue as regras da interpretação exegética da Escritura cristã e da própria exegese como operação de decifração, inclusive seu resultado.

Entretanto, ainda que a hermenêutica seja um elemento essencial dessa teologia, uma e outra não se identificam, já que o feminismo pode ser apreendido por outras análises diferentes da hermenêutica. Mais adequado seria falar então de mediação hermenêutica, no sentido de que a hermenêutica auxiliar a articulação entre teologia feminista e suas fontes cristãs, conferindoIhe uma identidade peculiar.

Neste sentido, é adequada a expressão teologia feminista, à medida em que ela sublinha não um novo método ou paradigma ${ }^{8}$, mas uma nova perspectiva de relação entre a Comunidade de vida e a escritura, entre o passado e o presente. Trata-se de maneira diferente de entender a hermenêutica dos textos teológicos, como a Bíblia, a exegese, a tradição, os Padres da Igreja, a liturgia, os textos do Magistério e dos Concílios.

\footnotetext{
${ }^{7}$ Há muitos estudos sobre a hermenêutica teológica feminista, principalmente na América Latina. Aqui apontamos alguns deles, somente a modo indicativo: CEBI, 2000; DEIFELT, 1992; TABORDA, 1990, p. 311-337; RUSSELL,1995, p. 11-20. O que temos percebido nestes diferentes estudos é a tendência a compreender a teologia feminista simplesmente como hermenêutica, como se todo o retrospecto e a prospecção da teologia feminista pudessem ser lidos como uma hermenêutica teológica. Isso é muito claro em: TAMEZ, 2004, p. 41-65. 8 "As ciências evoluem por rupturas, substituindo paradigmas por outros, como mostrou T. Kuhn. Ao contrário, a reflexão teológica se dá por continuidade, por um desenvolvimento contínuo e um aprofundamento permanente dos dados e intuições, incluindo o resgate das doutrinas errôneas" (BOFF, 1998, p. 259).
} 


\section{A hermenêutica feminista da suspeita}

Ainda que a hermenêutica feminista não tenha introduzido um método novo, em compensação, ela instaura dois novos critérios à hermenêutica teológica. Eles são apontados pelo documento da Pontifícia Comissão Bíblica, de abril de 1993, A interpretação da Bíblia na Igreja (tradução em 2004). Um deles é o sociológico, porque se trata de hermenêutica que se apoia na análise das sociedades da época dos textos sagrados, como elas eram estratificadas e qual a posição que as mulheres nelas ocupavam. O outro, é o "critério feminista" cujas origens remontam os movimentos de libertação das mulheres no âmbito mais geral da teologia da libertação. O documento acrescenta sobre este segundo critério: "Ele utiliza uma hermenêutica da suspeita: tendo a história sido regularmente escrita pelos vencedores, para encontrar a verdade não se deve confiar nos textos, mas procurar neles indícios que revelem outra coisa" (PONTIFÍCIA COMISSÃO BÍBLICA, 2004, p. 79-80, grifos nossos).

Algo central neste último critério é a referência explícita aos movimentos de libertação e, em especial, à teologia da libertação. Valeria dizer, ainda, que a reflexão teológica feita pelas mulheres na América Latina é que perfaz em grande medida essa hermenêutica, ainda que nem toda ela tenha necessariamente este cariz.

Trata-se de uma hermenêutica da suspeita, porque "não confia nos textos", embora não afirme que eles sejam somente uma invenção dos vencedores. Esta suspeita não envolve, por outro lado, renunciar à busca da verdade. Se a leitura bíblica da hermenêutica da suspeita fosse redutível a um desdobramento do perspectivismo nietzscheano, por exemplo, talvez tivesse que renunciar à busca da verdade revelada, limitando-se a dizer que ela não passa de uma verdade dos vencedores da história. O que a hermenêutica feminista da suspeita propõe é que a verdade revelada pode ser encontrada em outro lugar onde normalmente ela é identificada.

Como ressalta uma de suas expoentes, Elsa Tamez (2004, p. 62), a partir desta modalidade de hermenêutica, "suspeita-se do texto e do contexto do texto". Buscam-se nas entrelinhas as motivações que levaram à manutenção 
de textos relativamente favoráveis às mulheres em um contexto fortemente patriarcal. Além disso, suspeita-se dos estereótipos constituídos entre os seres humanos que acentuam a superioridade dos homens sobre as mulheres. Um dos desdobramentos dessa hermenêutica da suspeita é o que se detém na reavaliação dos textos bíblicos.

Conforme ainda Teresa Mee, a estratégia da suspeita tem dupla função. Uma negativa que consiste em desmascarar o caráter androcêntrico e o objetivo opressor do texto bíblico. Para isso, são discutidas as traduções, silêncios, contradições, argumentações, prescrições do texto, bem como discursos da Bíblia sobre gênero, etnia, classe ou cultura. Essa estratégia tem uma função positiva ao ocupar-se da reconstrução dos modelos em termos de retórica crítica, procurando entender tradições e textos bíblicos como uma herança viva. Assevera a autora que "tal herança não legitima a opressão patriarcal, mas tem a capacidade de promover práticas libertadoras de comunidades de fé" (MEE, 2000, p. 41).

A hermenêutica da suspeita é uma forma nova de se fazer teologia pelo privilégio de categorias interpretativas heurísticas, tais como: cotidiano, corporeidade, sexualidade, vida, simbolismo, alteridade, mulher, homem, androcentrismo, patriarcado e assim por diante. Vale ser lembrado que esse fazer teológico não tem a pretensão de universalidade, característica de outras formas de elaboração teológica. Seu escopo maior não é se posicionar paralelamente à interpretação teológica tradicional do ponto de vista da teoria, e sim efetuar a desconstrução de quaisquer interpretações que legitimem, na prática, uma sociedade de desiguais.

No entender de Ivone Gebara (1998), a hermenêutica propriamente teológica designa a articulação de sentido que se expressa em uma diversidade de discursos, os quais, por sua vez, visam apontar a necessidade humana de se viver melhor e em relações menos estreitas e preconceituosas. A hermenêutica da suspeita atém-no no resgate interpretativo de uma verdade profunda nos textos sagrados que foi propositalmente escondida, imprescindível para a construção de relações menos desiguais e reveladoras da vontade de Deus. 
A aventura pelos textos bíblicos antiquíssimos em busca de significados recônditos que reconheçam a dignidade das mulheres supõe arriscar-se a conviver com uma dupla marginalização. A primeira é a marginalização sobre as teólogas cristãs, geralmente imbuída da mentalidade patriarcal e sua interpretação antifeminista da Bíblia. A segunda, consiste na marginalização ad intra por parte das próprias feministas, conforme expressa L. M. Russell (1995, p. 14): “estão marginalizadas em grande medida do âmbito acadêmico feminista porque continuam sustentando o valor dos materiais bíblicos, apesar de sua tendência patriarcal contra as mulheres".

Reler a tradição bíblico-cristã a partir de uma perspectiva profética para a sociedade e para a Igreja envolve assumir o risco dessa dupla marginalização. Além disso, a hermenêutica da suspeita procura se afastar de duas tendências que se utilizam do método fundamentalista de interpretação da Bíblia, por identificarem texto e mensagem:

\begin{abstract}
A interpretação bíblica antifeminista, por longo tempo praticada e que em parte ainda subsiste, assume os dados bíblicos relativos à mulher, que interpreta na linha da interpretação patrística e escolástica, chegando a afirmar a inferioridade, ou a subordinação, ou a submissão, ou, de todo modo a complementaridade da mulher com relação ao homem. A interpretação bíblica feminista pós-cristã também parte dos dados bíblicos, como foram lidos pela tradição eclesiástica, mas chega à conclusão de que a Bíblia, ensinando a subordinação/sujeição da mulher ao homem, é irremediavelmente patriarcal (GIBELLINI, 1992, p. 91).
\end{abstract}

A hermenêutica da suspeita reconhece o patriarcado uma das mentalidades mais marcantes da antiga sociedade bíblica durante os aproximadamente mil anos da redação do texto sagrado judaico e cristão ${ }^{9}$. Essa hermenêutica busca denunciar não somente o patriarcalismo explícito, mas também as manifestações sutis da visão de mundo do escritor bíblico. Ao reconhecer essa tendência patriarcal dos materiais bíblicos, muitas teólogas

\footnotetext{
${ }^{9}$ Os primeiros fragmentos da Bíblia (AT) foram colocados por escrito somente durante o Reino Unido, isto é, sob Davi e Salomão (1040 a 931 a.C.). O primeiro livro do NT é a 1 a . Carta aos Tessalonicenses, escrita no ano 51 a.C. e o último livro, a $2^{a}$. Carta de Pedro, foi escrito no ano 120 d.C. Se tomamos os primeiros fragmentos do AT, escritos a partir de 1040 a.C. e o último texto canônico, escrito por volta do ano 120 d.C., teremos cerca de 1080 anos de redação. (Cf. BOHN GASS, 2007, p. 93-94).
} 
cristãs estudam os textos a partir de, pelo menos, três perspectivas diferentes, mas relacionáveis, segundo K. D. Sakenfeld :

1. Ocupam-se dos textos sobre mulheres para fazer face aos famosos textos usados 'contra' as mulheres; 2. Ocupam-se da Bíblia de um modo geral (não dos textos sobre mulheres de um modo particular) para chegar a uma perspectiva teológica que ofereça uma crítica do patriarcado (alguns a chamariam 'perspectiva de libertação'). 3. Ocupam-se dos textos sobre mulheres para aprender da história e das narrativas de mulheres antigas e modernas que viveram em culturas patriarcais (SAKENFELD, 1995, p. 66).

Se tomarmos a segunda dessas perspectivas, observaremos que no conjunto dos livros sagrados encontram-se posições paradoxais ${ }^{10}$ acerca da representação cultural e simbólica das mulheres e dos homens, oscilando entre a criação de desigualdades e o reconhecimento da igualdade.

Uma das grandes questões da hermenêutica da suspeita é a que segue: ao se considerar que tanto no Antigo como no Novo Testamento há indícios, ainda que escassos, que ressaltam a importância afirmativa das mulheres para a sociedade e para a religião (especialmente para as igrejas cristãs), questionase a razão pela qual na interpretação da tradição teológica judaico-cristã bem como nos ritos litúrgicos, predominaram justamente os elementos negativos? Diante dessa questão, uma das respostas mais comuns tem sido mostrar que, se do ponto de vista da roupagem cultural e sua influência na teologia predominaram valorações e juízos negativos a respeito das mulheres, já da perspectiva da mensagem divina, lida pela hermenêutica da suspeita, eles são injustificáveis.

Nos limites deste artigo, nosso propósito não é destacar alguns destes indícios pela própria incursão ao texto bíblico, como fizemos em outras oportunidades. Nosso intuito é antes destacar como a hermenêutica da suspeita pode ser identificada na teologia feminista latino-americana.

Nesse sentido, uma das pensadoras que mais tem se preocupado em fazer a leitura da Bíblia a partir da hermenêutica feminista da suspeita é Elsa

10 GIBELLINI (1992, p. 91), avaliando Gn 2- 3, aponta-os como textos clássicos da interpretação patriarcal. De acordo com ele, desses relatos "é fácil deduzir a inferioridade ôntica e ética da mulher". 
Tamez. Em sua obra Luchas de poder en los Orígenes del cristianismo - Un estudio de la Primeira Carta a Timóteo (TAMEZ, 2005), ela analisa o cristianismo primitivo pelo viés das lutas relacionadas à posição social dos membros da comunidade, das relações conflitivas entre homens e mulheres pela liderança, assim como pelas disputas teológicas e estilos de vida da comunidade.

$\mathrm{Na}$ América Latina, houve um despertar para a releitura dos textos bíblicos desde o início da teologia feita pelas mulheres. Não se trata de procurar na Bíblia curiosidades, mas a busca de:

[...] sentidos libertadores que iluminem o caminhar daqueles que estão descontentes com a realidade vivida (econômica, política, social, cultural, eclesial ou religiosa), e ecoa como uma forma diferente de ser humano e de viver como humanos aqui e agora (TAMEZ, 2005, p. 13).

A hermenêutica da suspeita oportuniza a descoberta de textos sagrados que valorizam o papel efetivo das mulheres no espaço religioso, bem como analisa a desconstrução de textos potencial ou explicitamente opressores. Lembra Elsa Tamez que o princípio orientador da teologia feminista em nosso continente é a opção de Deus pelos pobres e marginalizados, tal como indicada pela vida de Jesus. Este princípio está supostamente em relação de oposição com alguns textos das primeiras comunidades cristãs, particularmente a Primeira Carta a Timóteo, na qual o autor da carta parece optar pelo rico.

Tamez considera que a Primeira Carta a Timóteo expressa um tipo de fundamentalismo e patriarcalismo muito estranho às comunidades latinoamericanas. Ressalta ela: "essa atitude de opção pelos pobres é rompida quando entra o fundamentalismo, quando mediam outros interesses ou, simplesmente, quando a graça de Deus não mais tem lugar e passa a ser exigida a obediência em troca de dita opção" (TAMEZ, 2005, p. 14).

A partir da exegese, Elsa Tamez articula de forma coerente a dupla contextualização na leitura dos textos bíblicos, a saber: a época da escrita e o contexto da leitura do texto (horizonte da libertação). Conforme uma perspectiva que tem permeado os diferentes giros hermenêuticos da teologia feminista, ela procura desconstruir o machismo e as identidades falsas da sociedade patriarcal para, em seguida, propor a reconstrução de novas relações entre mulheres e homens no horizonte da América Latina. 
Lembra Tamez que a Primeira carta a Timóteo, assim como a Carta a Tito e a Primeira de Pedro, são escritos evitados nas leituras comunitárias da Bíblia. A razão disso é que, ao contrário de outros livros bíblicos, elas não oferecem palavras de alento e esperança aos excluídos/as. Há perícopes que incomodam aqueles que estão acostumados a ler a Bíblia a partir do princípio da opção preferencial de Deus pelos pobres. Por exemplo, a de que os escravos devem considerar a seus senhores dignos de toda honra e que, se estes se converteram à fé cristã, devem servi-los ainda melhor (cf. Tm 6,1-2). Entretanto, os versículos mais problemáticos são aqueles referidos às mulheres (1 Tm 2,11-12), posto que nas comunidades cristãs e associações de bairros dos contextos periféricos - como é o caso latino-americano - são elas as protagonistas. Segue-se a importância de uma releitura contextualizada dessa Carta para poder compreender em que sentido ela pode ser entendida como uma fala divina.

Esta é somente uma síntese figurativa da maneira como procede a hermenêutica da suspeita. Ela não pretende fazer uma leitura às avessas da Bíblia pela qual seriam ressaltadas as mulheres, em prejuízo dos homens. Ao percorrer o texto bíblico, trata-se de analisar a possibilidade de uma teologia que ressalte a completude ${ }^{11}$ entre elas e eles. Em vez de exacerbar os antagonismos que ferem e dividem os seres humanos, a reflexão incide sobre os elementos que os integram, como podemos observar no movimento e prática de Jesus que, em muitos aspectos, revoluciona a mentalidade judaica patriarcal de seu tempo. Uma das consequências do movimento de Jesus é justamente a recuperação da igualdade substancial entre homens e mulheres, sem deixar de lado suas diferenças acidentais.

\footnotetext{
${ }^{11}$ Completude quer dizer "uma plena equivalente natureza e personalidade humanas", ainda que com suas modalidades próprias. Essa postura difere do modelo da "complementaridade dos sexos", porque este considera a mulher como complemento do homem, permanecendo a humanidade masculina como normativa. O modelo da complementaridade é suscetível de interpretação e prática subordinacionistas (GIBELLINI, 1992, p. 114-115).
} 


\section{Considerações finais}

A incursão pelos movimentos da hermenêutica teológica feminista objetiva propor outra leitura daquelas passagens nas quais a interpretação tradicional naturalizou a desvalorização das mulheres.

Essa hermenêutica ajuda a distinguir entre a mensagem revelada e a roupagem cultural na qual são visíveis o androcentrismo semítico e sua representação patriarcal. Ela também evidencia que, se em grande parte dos textos as mulheres são menosprezadas, mesmo assim é possível encontrar passagens significativas que denunciam sua dominação e sujeição. A hermenêutica feminista reconstitui ainda os movimentos da Igreja primitiva nos quais vemos mulheres atuando decisivamente no âmbito público das comunidades. Apesar da riqueza da mensagem libertadora trazida por Jesus Cristo diante da mentalidade patriarcal da cultura semita, os rumos da história — inclusive da história da Igreja — não mudaram significativamente no que concerne à situação das mulheres.

A hermenêutica teológica feminista adverte que é preciso se precaver para não essencializar o que é culturalmente construído. Além disso, como chama a atenção Ivone Gebara, é mister a construção de relações humanas livres, justas, solidárias, ternas e, acima de tudo, a valorização da pessoa humana. Os textos bíblicos, como tantos outros textos antigos, conservam um caráter oculto e misterioso. "Um texto nunca permite, pois, descobrir suas intenções ocultas de forma clara: ele sempre escapa das tentativas de se absolutizar sua interpretação, como se fosse a única e última possibilidade de explicar seu sentido" (GEBARA, 1998, p. 111). O texto sagrado é mediação para a revelação de nós mesmas/os.

A hermenêutica teológica feminista tem como escopo a recuperação de significados outros que permaneceram tácitos ou imperceptíveis das demais hermenêuticas teológicas. Seu elemento inovador pode ser identificado pelo uso da imaginação criativa que reconstrói o pré-texto (contexto) dos textos reconstruindo a condição histórica das mulheres que leem a Bíblia. Acima de tudo, essa hermenêutica procura percorrer os diversos movimentos de modo 
circular e espiral, como lembra E. S. Fiorenza (2009), para que mulheres e homens possam revelar sua fecundidade própria. Com isso, busca-se transcender quaisquer mecanismos de hierarquizações a fim de repensar 0 que nos propõe o livro do Gênesis quando sugere que, no princípio, Deus criounos como unidade diversificada e pluralidade una, sem a pretensão de hierarquizar o relacionamento humano. Esse Deus, cujo modelo é apreendido pelas suas imagens (os seres humanos, não pode ser igualmente nomeado somente com atributos desdobrados da mentalidade patriarcal.

A hermenêutica da suspeita não se limita a apontar a ausência das mulheres ou seu papel meramente coadjuvante no texto bíblico ou na história da Igreja, como também pergunta sobre seu lugar e as funções que ocupam nas comunidades cristãs primitivas. Essa hermenêutica encontra sua originalidade não tanto pela busca de novas fontes, mas antes, pela tentativa de lê-las a partir de novos olhares.

\section{Referências}

BOFF, C. Teologia e Prática: Teologia do Político e suas Mediações. Petrópolis: Vozes, 1978.

BOHN GASS, L. Porta de entrada: A serviço da leitura libertadora da Bíblia. 9. ed. São Leopoldo: CEBI; São Paulo: Paulus, 2007.p. 93-94. (Série Uma introdução à Bíblia, v.1)

BORNKAMM, G. Bíblia: Novo Testamento - introdução aos seus escritos no quadro da história do cristianismo primitivo. São Paulo: Editora Teológica, 2003.

BULTMANN, R. Jesus Cristo e mitologia. São Paulo: Editora Novo Século, 2000.

CEBI. Hermenêutica Feminista e Gênero, n. 155/156, São Leopoldo/RS, 2000.

CROATTO, S. J. Hermenêutica bíblica: Para uma teoria da leitura como produção de significado. São Leopoldo, RS: Sinodal; São Paulo: Paulinas, 1986.

CULLMAN, O. Cristologia do Novo Testamento. São Paulo: Editora Líber, 2001;

DEIFELT, W. Os primeiros passos de uma hermenêutica feminista: a Bíblia das Mulheres, editada por Elisabeth Cady Stanton. Estudos Teológicos, n. 32, p. 5-14, 1992.

FERRARIS, M. Historia de la hermenéutica. Madrid: Ediciones Akal, 2000. 
FIORENZA, E. S. Caminhos da sabedoria: uma Introdução à Interpretação bíblica feminista. São Bernardo do Campo, SP: Nhanduti Editora, 2009.

GEBARA, I. Hermenéutica Bíblica Feminista. In: TEPEDINO, A. M.; AQUINO, M. P. (Orgs.). Entre la indignación y la Esperanza. Teología Feminista Latinoamericana. Bogotá: Indo-American Press Service Ltda, 1998. p. 90-111.

GEFFRÉ, C. Como fazer teologia hoje: hermenêutica teológica. São Paulo: Paulinas, 1989.

GIBELLINI, R. A outra voz da teologia: esboços e perspectivas de teologia feminista. In: LUNEN-CHENU, M. T.; GIBELLINI, R. Mulher e Teologia. São Paulo: Loyola, 1992. p. 71-133.

HEIDEGGER, M. Ser e Tempo. Trad. Fausto Cstilho. Campinas: Editora da UNICAMP, 2012. (Muitilíngues de Filosofia UNICAMP).

MEE, T. O que consideramos que seja uma Hermenêutica de Gênero? In: AA. VV. Hermenêutica Feminista e Gênero. São Leopoldo: CEBI, 2000. p. 39-42.

MARTÍNEZ, J. M. Hermenéutica bíblica: cómo interpretar las sagradas escrituras. Barcelona: Terrasa, 1984.

NOGUEIRA, P. Os métodos histórico-críticos: pressupostos e pautas para renovação, Estudos teológicos, v. 59, n.2, 2019. p. 296-310.

PONTIFÍCIA COMISSÃO BÍBLICA. A interpretação da Bíblia na lgreja. 6. ed. São Paulo: Paulinas, 2004.

RICOEUR, P. De l'interpretation. Essai sur Freud. Seuil: Paris, 1965.

RUSSEL, L. M. Interpretación feminista de la Bíblia. Bilbao: Desclée de Brouwer, 1995.

SAKENFELD, K. D. Usos feministas de los materiales bíblicos. In: RUSSEL, L. M. (Ed.) Interpretación bíblica feminista de la Biblia. Trad. Ramón Alfonso Díez Aragon. Bilbao: Desclée de Brouwer, 1995. p. 65-76.

TABORDA, F. Feminino e teologia feminista no primeiro mundo - breve panorâmica para uma primeira informação, Perspectiva Teológica, n. 22, p. 311-337, 1990.

TAMEZ, E. La hermenêutica bíblica feminista en Iberoamérica. In: MARCOS, S. (Org.). Religión y Gênero. Madrid: Editorial Trotta, S.A. 2004, p. 41-65.

TAMEZ, E. Luchas de poder en los Orígenes del cristianismo: Un estudio de la Primera Carta a Timoteo. Santander: Sal Terrae, 2005. 